\title{
JOURNAL OF ANIMAL SCIENCE
}

The Premier Journal and Leading Source of New Knowledge and Perspective in Animal Science

\section{Effect of peripartal feeding strategy on colostrum yield and composition in sows}

R. Decaluwé, D. Maes, A. Cools, B. Wuyts, S. De Smet, B. Marescau, P. P. De Deyn and G. P. J. Janssens

J ANIM SCI 2014, 92:3557-3567.

doi: 10.2527/jas.2014-7612 originally published online June 30, 2014

The online version of this article, along with updated information and services, is located on the World Wide Web at:

http://www.journalofanimalscience.org/content/92/8/3557

WwW.asas.org 


\title{
Effect of peripartal feeding strategy on colostrum yield and composition in sows ${ }^{1}$
}

\author{
R. Decaluwé, $* \dagger^{2}$ D. Maes, $\dagger$ A. Cools, $* \dagger$ B. Wuyts, $\$$ \\ S. De Smet,§ B. Marescau,\# P. P. De Deyn,\# and G. P. J. Janssens*
}

*Department of Nutrition, Genetics and Ethology, Faculty of Veterinary Medicine, Ghent University, 9820 Merelbeke, Belgium; $\dagger$ Department of Obstetrics, Reproduction and Herd Health, Faculty of Veterinary Medicine, Ghent University, 9820 Merelbeke, Belgium; \$Department of Clinical Biology, Microbiology and Immunology, Faculty of Medicine and Health Sciences, Ghent University, 9000 Ghent, Belgium; $\S$ Department of Animal Production, Faculty of Bioscience Engineering, Ghent University, 9090 Melle, Belgium; and \#Laboratory of Neurochemistry and Behavior, Institute Born-Bunge, University of Antwerp, 2000 Antwerp, Belgium

\begin{abstract}
Research showed a positive association between back fat (BF) change the week before farrowing and colostrum yield (CY). This study tested the causality of this association, hence to optimize $\mathrm{CY}$ by altering the sows' peripartal feeding strategy. Sows were randomly divided into 2 treatment groups at d 108 of gestation. The first group ( $\mathrm{L}, n=28)$ received $1.5 \mathrm{~kg}$ feed $\cdot \mathrm{d}^{-1}$, the second group $(\mathrm{H}, n=22)$ received 3 times $1.5 \mathrm{~kg}$ feed $\cdot \mathrm{d}^{-1}$ until farrowing. Daily feed intake and CY were measured. Colostrum was analyzed for nutrient composition, AA and fatty acids, IgG and IgA. Sow serum was obtained at d 108 of gestation and d 1 of lactation after overnight fasting and analyzed for NEFA, (iso)butyrylcarnitine (C4), creatinine, urea, 3-OH-butyrylcarnitine (3-OH-C4), IgG, and IgA. Based on BF at d 108, sows were divided into body condition (BC) groups: skinny ( $<17 \mathrm{~mm}, n=15)$, moderate (17 to $23 \mathrm{~mm}, n=21)$, fat $(>23 \mathrm{~mm}, n=14)$. We performed ANOVA with treatment and $\mathrm{BC}$ as fixed factors and Scheffé post-hoc test. The week before farrowing, the L group had the lowest daily feed intake (DFI; $1.5 \mathrm{~kg}$ ), and within the $\mathrm{H}$ group, fat sows $(3.8 \mathrm{~kg})$ had a lower DFI than skinny sows $(4.3 \mathrm{~kg}$; $p=0.006)$. The $\mathrm{H}$ group tended to have a greater total $\mathrm{CY}$
\end{abstract}

$(P=0.074)$ and had a greater $\mathrm{CY} / \mathrm{kg}$ liveborn piglet $(P=$ $0.018)$ than the L group. Compared with sows in moderate $\mathrm{BC}$, fat sows had a lower total $\mathrm{CY}(P=0.044)$ and a lower $\mathrm{CY} / \mathrm{kg}$ liveborn piglet $(P=0.005)$. The $\mathrm{H}$ group had a greater concentration of lactose $(p=0.009)$ and n-3 PUFA $(p<0.001)$ but a lower concentration of protein $(p=0.040)$ in colostrum than the L group. The concentration of $\operatorname{IgG}$ and $\operatorname{IgA}$ did not differ between treatment and BC groups. Serum parameters at d 108 were similar between the treatment groups and BC groups. At d 1, the $\mathrm{H}$ group mobilized less body fat (NEFA: $p=0.002$ ) and protein (creatinine: $p<0.001, \mathrm{C} 4: p=0.016$ ) reserves but had a greater ratio urea:NEFA $(p<0.001)$ and less ketone bodies (3-OH-C4: $p<0.001)$ compared with the L group. This indicates a more balanced entry of metabolites in the citric acid cycle and thus a better support of the maternal peripartal metabolism in the $\mathrm{H}$ group. Serum parameters did not differ between $\mathrm{BC}$ groups. Both $\mathrm{CY}$ and composition can be influenced by the peripartal feeding strategy and BC. The highest CY and most beneficial colostrum composition were obtained when sows entered the farrowing unit in a moderate $\mathrm{BC}$ and were provided a high peripartal feeding strategy.

Key words: colostrum, energy, feeding strategy, peripartal, protein

(C) 2014 American Society of Animal Science. All rights reserved.

J. Anim. Sci. 2014.92:3557-3567 doi:10.2527/jas2014-7612

\section{INTRODUCTION}

Approximately $30 \%$ of sows produce insuf-

${ }^{1}$ The authors would like to acknowledge the financial support of the Agency for Innovation by Science and Technology in Flanders (IWT; 101183).

${ }^{2}$ Corresponding author: ruben.decaluwe@ugent.be

Received January 16, 2014.

Accepted May 18, 2014. ficient colostrum for her litter (Foisnet et al., 2010; Decaluwé et al., 2013). Assessing this problem could be rather complicated as the sows' colostrum yield (CY) is associated with sow, piglet, and environmental traits (Farmer and Quesnel, 2009) and strategies 
that increase CY should not have negative effects on colostrum composition. Previous results show that for similarly managed sows there is no association between CY and colostrum composition (Decaluwé et al., 2013) but it might still be that increasing CY through changes in the management alters colostrum composition as adding fat to sows' diet increases the colostral fat content (Jackson et al., 1995) and milk production (Coffey et al., 1982).

Martineau et al. (2013) report that a good transition from gestation to lactation metabolism is essential for a good lactation performance. During late gestation, the sow's metabolism adapts by sparing glucose for fetuses and lactation while the sow herself starts using more ketogenic energy substrates (Robert and Kensinger, 1998). When the supply of nutrients through diet is low, sows become catabolic, which increases the use of ketogenic energy substrates. This can result in ketosis (Theil et al., 2013), and although this generally does not result in clinical symptoms, it might lead to suboptimal production. Colostrum is produced during the last month of gestation but mainly during the last week before farrowing (Devillers et al., 2006) and the back fat (BF) change during this last week of gestation is positively associated with CY (Decaluwé et al., 2013).

The hypothesis of the present study is, therefore, that the feeding strategy a week before farrowing could affect the maternal metabolism and the level of nutrients available for the mammary gland resulting in a different CY.

\section{MATERIAL AND METHODS}

The experiment was approved by the ethical committee of the Faculty of Veterinary Medicine, Ghent University (EC2012/099), Belgium.

\section{Study Population and Experimental Design}

The study was conducted from July until September 2012 in a commercial farm comprising 1,700 PIC sows and practicing a 2 -wk batch system. Ninety-five sows (parity 2 to 7 ) equally divided over 2 batches were observed from d 85 of gestation until weaning. Only sows with a gestation length of 114 to $116 \mathrm{~d}$ were included in the study, and because estimating colostrum yield was labor intensive, the number of sows that could be monitored correctly at the same time was limited. Therefore, we collected data of 50 sows. The day of first insemination was defined as $\mathrm{d} 0$ of gestation, the day of parturition as the last day of gestation and $\mathrm{d} 0$ of lactation.

From d 29 until d 106 of gestation, sows were similarly managed and group housed with 15 sows per pen. Two feeders that dropped a small amount of the gestation diet (meal) at regular intervals throughout the day were

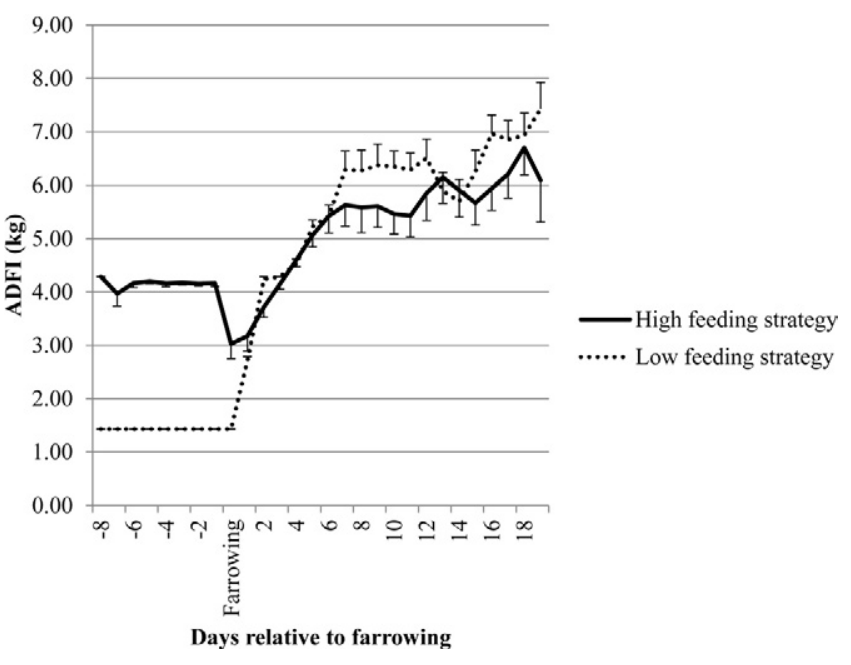

Figure 1. The ADFI patterns of both treatment groups from d 108 of gestation until the end of lactation are shown. Error bars represent the SEM.

present per pen. The total amount of feed provided was on average $2.5 \mathrm{~kg} \cdot \mathrm{sow}^{-1} \cdot \mathrm{d}^{-1}$. Sows were moved to the farrowing unit on d 107 of gestation, where they were housed individually in conventional farrowing crates until weaning. Floor heating and an infrared lamp were used to create a microclimate for the piglets.

Upon arrival in the farrowing unit, sows were stratified for parity, change in BF between d 85 and d 108 of gestation, and $\mathrm{BF}$ at $\mathrm{d} 108$ of gestation and randomly divided into 2 treatment groups. The first group received a high peripartal feeding strategy $(\mathbf{H}, n=22): 1.5 \mathrm{~kg}$ of a transition diet (meal) 3 times a day $(0730 \mathrm{~h}, 1130 \mathrm{~h}$, and $1630 \mathrm{~h}$ ) between d 108 of gestation and d 3 of lactation. The second group received a low peripartal feeding strategy $(\mathbf{L}, n=28): 1.5 \mathrm{~kg}$ of the same transition diet once a day at $0730 \mathrm{~h}$ until day of farrowing. At $\mathrm{d} 1$ of lactation, the L group was fed twice and at $\mathrm{d} 2$ of lactation they were fed 3 times $1.5 \mathrm{~kg}$ of the transition diet. Approximately $4 \mathrm{~h}$ after each meal, feed leftovers were recorded. Starting from $\mathrm{d} 3$ of lactation until weaning, all sows received the same lactation diet (meal) 4 times a day, of which the amount gradually increased. When a sow had not finished the meal of the previous day, the trough was emptied and a 10 to $20 \%$ smaller amount of fresh feed was given. The feeding pattern of both treatment groups between d 108 of gestation and weaning is shown in Fig. 1. During the entire experiment, sows had free access to fresh drinking water (drinking nipple flow 1.5 to $2 \mathrm{~L} / \mathrm{min}$ ).

Farrowing induction was not applied, and farrowing intervention was minimized to manual extraction when the birth interval between 2 piglets exceeded $1 \mathrm{~h}$. No oxytocin was administered during parturition because this might interfere with mammary secretion (Ellendorf et al., 1982). No additional help or care was given to the piglets unless there was a risk for them of getting crushed. On $\mathrm{d} 2$ of lactation, litters were standardized to $11 \pm 1$ piglet by cross 
fostering. From d 2 of lactation, piglets were offered creep feed. The feed intake of the piglets was not measured.

\section{Parameters and Measurements}

All measurements of BF thickness were performed by the same person on standing sows at the $\mathrm{P} 2$ position (Maes et al., 2004) at both sides of the spinal cord after hair removal using a digital BF indicator (Renco Lean Meter, S.E.C. Repro Inc., Ange-Gardien-de-Rouville, Québec, Canada). Values from the 2 measurements were averaged to obtain a single $\mathrm{BF}$ measurement. The $\mathrm{BF}$ was measured at d 85 and d 108 of gestation, at d 1 of lactation, and at weaning.

The CY was calculated as the sum of the individual piglet's colostrum intake within a litter as described by Devillers et al. (2004) using the following variables: birth weight $\left(\mathbf{B W}_{\mathbf{B}}, \mathrm{kg}\right)$, weight at 17 to $24 \mathrm{~h}$ of age $\left(\mathbf{B W}_{\mathbf{2 4}}, \mathrm{kg}\right)$, duration of colostrum intake $(\mathbf{t}$ in min and with $17 \mathrm{~h} \leq$ $\mathrm{t} \leq 25 \mathrm{~h}$ ), and time between birth and first suckling (tFS, min). The tFS was estimated to be $35 \mathrm{~min}$, which was based on observations from a previous study performed at the same farm (Decaluwé et al., 2013). As explained by Devillers et al. (2004), an error of $15 \mathrm{~min}$ of tFS induces a miscalculation of intake by the piglet of $6 \mathrm{~g} / \mathrm{kg}$ $\mathrm{BW}_{\mathrm{B}}$ or less than $2 \%$ error. The used regression equation was: colostrum intake $=-217.4+0.217 \times \mathrm{t}+1861,019 \times$ $\mathrm{BW}_{24} / \mathrm{t}+\mathrm{BW}_{\mathrm{B}} \times(54.80-1,861,019 / \mathrm{t}) \times(0.9985-3.7 \times$ $10^{-4} \times \mathrm{t}_{\mathrm{FS}}+6.1 \times 10^{-7} \times \mathrm{t}^{2} \mathrm{FS}$ ). When a piglet was born, the back of the piglet was dried with a paper towel and marked. Piglets were ear tagged, allowing identification. The umbilical cord was shortened when it was longer than approximately $15 \mathrm{~cm}$. After weighing, piglets were placed in the farrowing pen with their nose against the sow's vulva. The accuracy of the scale was $0.02 \mathrm{~kg}$.

Observed sow parameters were parity, gestation length, farrowing duration, number of total liveborn and stillborn piglets, and number of weaned piglets. Observed piglet parameters were birth interval, preweaning mortality, $\mathrm{BW}_{\mathrm{B}}, \mathrm{BW}_{24}$, and body weight at $\mathrm{d}$ $3, \mathrm{~d} 7$ and $\mathrm{d} 14$ of age and at weaning. Piglets were cross fostered after measuring the $\mathrm{BW}_{24}$ and from then on, litter weight gain was calculated per sow.

\section{Samples}

Feeds were sampled at the end of the study.

Sows' serum (serum cloth activator tubes, $18 \mathrm{~mL}$ ) and plasma (sodium fluoride:potassium oxalate tubes, $2 \mathrm{~mL}$ ) was collected by punction of the vena jugularis while restraining sows with a snare at $\mathrm{d} 108$ of gestation and at $\mathrm{d} 1$ of lactation before the morning meal after an overnight fasting period (minimum $10 \mathrm{~h}$ ). Samples were stored in iced water, subsequently centrifuged at $1000 \times$
Table 1. Fatty acid profile of the sows' transition diet and intake in both treatment groups

\begin{tabular}{lcccc}
\hline \hline & $\begin{array}{c}\text { Value/100 } \\
\text { g fatty } \\
\text { acids }\end{array}$ & $\begin{array}{c}\text { Value/100 } \\
\text { feed }\end{array}$ & $\begin{array}{c}\text { Daily } \\
\text { intake } \\
\text { Hariable }^{1}\end{array}$ & $\begin{array}{c}\text { Daily } \\
\text { intake }\end{array}$ \\
\hline SFA, g & 38.3 & 1.93 & 86.7 & 28.9 \\
LUFA, group & \\
L-6 PUFA, g & 26.6 & 1.34 & 60.4 & 20.1 \\
n-3 PUFA, g & 29.1 & 1.46 & 65.9 & 22.0 \\
Linoleic acid n-6 C18:2, g & 4.8 & 0.24 & 10.8 & 3.6 \\
Arachidonic acid n-6 C20:4, mg & 29.1 & 1.46 & 65.8 & 21.9 \\
Linolenic acid n-3 C18:3, g & 10.0 & 0.50 & 22.5 & 7.5 \\
EPA n-3 C20:5, mg & 4.6 & 0.23 & 10.4 & 3.5 \\
DHA n-3 C22:6, mg & 20.0 & 0.80 & 36.0 & 12.0 \\
(n-6):(n-3) PUFA & 50.0 & 2.70 & 121.5 & 40.5 \\
\hline
\end{tabular}

${ }^{1} \mathrm{EPA}=$ eicosapentaenoic acid; DHA= docosahexaenoic acid.

${ }^{2} \mathrm{H}=$ high feeding level during the peripartal period.

${ }^{3} \mathrm{~L}=$ low feeding level during the peripartal period.

$g$ for $15 \mathrm{~min}$ at room temperature, and stored frozen at $-20^{\circ} \mathrm{C}$ until further analysis.

Colostrum $(40 \mathrm{~mL})$ was collected from all teats of 1 side of the udder at $6 \mathrm{~h}$ after birth of the first piglet after an i.m. injection of $2 \mathrm{~mL}$ of oxytocin $(10 \mathrm{IU} / \mathrm{mL})$ $5 \mathrm{~min}$ before sampling. At the time of sample collection, 10 sows did not complete farrowing but they were also injected $2 \mathrm{~mL}$ of oxytocin. The colostrum samples were subdivided into 6 subsamples, frozen at $-20^{\circ} \mathrm{C}$, and stored until further analysis.

\section{Analyses of Samples}

Feed. Nutritional composition of the diets was analyzed according to the Association of Official Analytical Chemists methods (Thiex, 2002; ISO 5983-1, 2005; ISO 1443, 1973; ISO 5498, 1981). All percentages represent an as-fed basis. The gestation diet contained $89.9 \% \mathrm{DM}$, $2.4 \%$ of crude fat $(\mathbf{C F}), 13.5 \%$ of $\mathrm{CP}, 10.2 \%$ of crude ash (CA) and $8.0 \%$ of crude fiber (CFib). The transition diet contained 91.1\% DM, 4.4\% CF, 13.0\% CP, 8.9\% $\mathrm{CA}$, and $7.9 \%$ CFib. The lactation diet contained $89.6 \%$ DM, 3.3\% CF, 17.3\% CP, 10.4\% CA, and 3.7\% CFib. The creep feed of the piglets' diet contained $93.7 \% \mathrm{DM}$, $10.1 \% \mathrm{CF}, 19.7 \% \mathrm{CP}, 6.3 \% \mathrm{CA}$, and $4.3 \% \mathrm{CFib}$.

The fatty acid profile of the transition diet was determined as described by Stefanov et al. (2010) and is shown in Table 1.

Serum and Plasma. Serum was analyzed for urea, creatinine, NEFA, (iso)butyrylcarnitine (C4), 3-hydroxybutyryl-carnitine (3-OH-C4), IgG, and IgA. Plasma was analyzed for glucose. (Iso)butyrylcarnitine is a catabolite of AA that can be metabolized to oxaloacetate, which is needed to react with acetyl-CoA when entering the citric acid cycle (Michal, 1999a,b). Urea, creatinine, NEFA, 
and glucose were measured spectrophotometrically (Ultrospec IIE, LKB, Biochrom, Cambridge, England) using a commercial colorimetric diagnostic kit (references UR107 for urea, CR510 for creatinine, FA115 for NEFA, and GL2623 for glucose, Randox Laboratories, Crumlin, United Kingdom). Quantitative electrospray tandem MS was used to determine $\mathrm{C} 4$ and 3-OH-C4 as described by Zabielski et al. (2007). A porcine quantitative sandwich enzyme immunoassay technique was used to analyze $\operatorname{IgG}$ (dilution 1:100,000) and $\operatorname{IgA}$ (dilution 1:40,000; references A100 to 104 for IgG and A100 to 102 for IgA, Bethyl Laboratories Inc., Montgomery, TX). All samples were analyzed in duplicate. The intra and interassay were, respectively, 2.9 and $5.2 \%$ for urea, 2.8 and $2.9 \%$ for creatinine, 4.8 and $4.3 \%$ for NEFA, 9.6 and $9.5 \%$ for $\mathrm{C} 4$ and $3-\mathrm{OH}-\mathrm{C} 4,3.1$ and $6.3 \%$ for $\mathrm{IgG}$, and 3.2 and $9.8 \%$ for $\operatorname{IgA}$.

Colostrum. Colostrum was analyzed for its macronutrient, fatty acid and AA acid composition, IgG, and IgA. Nutritional composition (fat, protein, and lactose content) was estimated by Lactoscope FTIR Advanced type FTA3.0 (Delta Instruments, Drachten, Netherlands). Samples were diluted 1:2 with distilled water and calibrated curves were verified with Gerber and Kjeldahl analysis $\left(R^{2}\right.$ between FTIR and Gerber $=0.9975 ; R^{2}$ between FTIR and Kjeldahl $=0.9997)$. To determine the fatty acid profile, milk fat was extracted as described by Chouinard et al. (1997) and subsequently methylated and analyzed by gas liquid chromatography as described by Stefanov et al. (2010). The intra and interassay were, respectively, 0.24 and $0.23 \%$. For analysis of total AA, proteins and peptides in the colostrum samples were first hydrolyzed to break all peptide bounds. Therefore, colostrum samples were first dried with a Savant speed-vac system and then further dried into an exsiccator with potassium hydroxide platelets and phosphorus pentoxide. Next, $6 \mathrm{~N} \mathrm{HCl}$ containing $1 \%$ fenol and $5 \%$ thioglycol acid was added to the dried colostrum samples. Hydrolysis of the colostrum samples was then performed under inert conditions using nitrogen gas to prevent oxidative degradation of AA during acid hydrolysis and under vacuum. The samples were heated at $110^{\circ} \mathrm{C}$ for $24 \mathrm{~h}$ and subsequently dried under vacuum. To remove all acid traces the samples were washed several times with a solution of water, ethanol, and tri-ethylamine $(2: 2: 1 \mathrm{v} / \mathrm{v})$. To the dry hydrolysis product sampling buffer (lithium citrate buffer) was added and dilutions were made for the analysis of AA with a Biotronik LC 6001 Amino Acid Analyzer (Biotronik, Maintal, Germany). The ninhydrin method was used for colorimetric detection. In the analysis, we grouped the essential and nonessential AA according to Lewis (2001). A porcine quantitative sandwich enzyme immunoassay technique was used to analyze colostral IgG (dilution 1:500,000) and IgA (dilution 1:50,000) in duplicate (references A100 to 104 for IgG and A100 to
102 for IgA, Bethyl Laboratories Inc., Montgomery, TX). The intra and interassay were, respectively, 2.3 and $9.7 \%$ for $\operatorname{IgG}$, and 3.4 and $2.6 \%$ for IgA.

\section{Statistical Analysis}

All statistical analyses were performed using SPSS 19.0 (IBM Company Headquarters, Chicago, IL), considering statistical significance when $P<0.05$ (2-sided tests).

Normally distributed variables are reported as LSmean \pm SEM and not normally distributed variables as median \pm interquartile range. Normality of the data was analyzed with the Kolmogorov-Smirnov test, the Levene's test was used to verify homogeneity of variance.

Data were subjected to GLM with treatment group and body condition (BC) group as fixed factors. Interaction terms were tested, removed from the model if not significant, and only presented if significant $(p<0.05)$. Sows were assigned to 1 of $3 \mathrm{BC}$ groups according to their $\mathrm{BF}$ thickness at $\mathrm{d} 108$ of gestation: skinny $(<17 \mathrm{~mm})$, moderate $(7$ to $23 \mathrm{~mm})$ and fat $(>23 \mathrm{~mm}) \mathrm{BC}$. These 3 groups based on BC contained 15, 21, and 14 sows, respectively. The number of sows within the skinny, moderate, and fat $\mathrm{BC}$ group was 8,12 , and 8 within the L group, and 7, 9, and 6 within the $\mathrm{H}$ group, respectively. The number of sows in both treatment groups was not identical (L group: $n=28$, H group: $n=22$ ) because the number of sows that could be correctly observed while estimating colostrum yield was limited by the practical conditions. Normality and homogeneity of variance of the residuals were examined graphically and verified using the KolmogorovSmirnov test, Q-Q plot, and the Levene's test. To determine significant differences, a post-hoc Scheffé test was performed when appropriate. When data were not normally distributed, a Kruskall-Wallis analysis was performed and pairwise comparisons were executed when appropriate. The odds ratio for producing/consuming less than $160 \mathrm{~g}$ of colostrum per kg liveborn piglet, which is proposed as the minimum required amount of colostrum intake (Le Dividich et al., 2005), was calculated for the L group compared to the H group.

\section{RESULTS}

\section{Feed Intake and Back Fat Thickness}

An interaction effect was observed between treatment and $\mathrm{BC}$ group in ADFI between $\mathrm{d} 108$ of gestation and $\mathrm{d}$ 1 of lactation (Fig. 2). It was lower for the L group (1.4 \pm $0 \mathrm{~kg}$ ) than for the $\mathrm{H}$ group, but within the $\mathrm{H}$ group, skinny sows $(4.3 \pm 0.01 \mathrm{~kg})$ had a greater ADFI than fat sows $(3.8 \pm 0.2 \mathrm{~kg} ; P=0.006)$ and tended to have a greater ADFI than sows in moderate $\mathrm{BC}(4.0 \pm 0.07 \mathrm{~kg} ; P=$ 0.092). The ADFI during lactation did not differ across 
treatment and $\mathrm{BC}$ groups. Total feed intake between $\mathrm{d} 108$ of gestation and weaning tended $(P=0.054)$ to be greater in the $\mathrm{H}$ group than in the $\mathrm{L}$ group (Table 2).

The $\mathrm{L}$ group lost more $\mathrm{BF}$ than the $\mathrm{H}$ group $(P=0.001)$ between $\mathrm{d} 108$ of gestation and $\mathrm{d} 1$ of lactation and this was independent of $\mathrm{BC}$ group. The $\mathrm{L}$ group lost less $\mathrm{BF}$ during lactation $(P=0.072)$, as did skinny sows compared to sows in moderate $(P=0.046)$ and fat $\mathrm{BC}(P=0.003)$. The loss of BF during the entire period of observation (d 108 of gestation until weaning) did not differ between treatment groups $(P=0.188)$, but skinny sows lost less BF than sows in moderate $(P=0.003)$ or fat $\mathrm{BC}(p<0.001)$. The $\mathrm{BC}$ of sows at $\mathrm{d} 108$ of gestation was similar to the $\mathrm{BC}$ at $\mathrm{d} 85$ of gestation. Furthermore, skinny sows lost BF between d 85 and $\mathrm{d} 108$ of gestation, whereas fat sows gained BF during this period $(P=0.005)$. Feed intake, back fat, and back fat changes are presented in Table 2.

\section{Colostrum Yield}

The CY was affected by both treatment and BC at d 108 of gestation with no interaction observed. Sows of the $\mathrm{H}$ group tended to have a greater total CY $(P=$ $0.074)$ and secreted more colostrum per kg liveborn piglet $(P=0.018)$ than sows of the L group. Compared with sows in moderate $\mathrm{BC}$, fat sows had a lower total $\mathrm{CY}(P=$ 0.044), a lower CY per liveborn piglet $(P=0.016)$, and a lower CY per kg liveborn piglet $(P=0.005)$. Colostrum yield parameters are shown in Table 3.

Fourteen percent of the $\mathrm{H}$ group and $32 \%$ of the $\mathrm{L}$ group produced less than $160 \mathrm{~g}$ colostrum per kg liveborn piglet. Odds of a sow producing less than $160 \mathrm{~g}$ colostrum per $\mathrm{kg}$ liveborn piglet were 3.0 times higher in L group than in the $\mathrm{H}$ group. Twenty-seven percent of piglets born in the $\mathrm{H}$ group and $34 \%$ of the piglets born in the $\mathrm{L}$ group consumed less than $160 \mathrm{~g}$ colostrum per $\mathrm{kg} \mathrm{BW}_{\mathrm{B}}$. Odds of a piglet consuming less than $160 \mathrm{~g}$

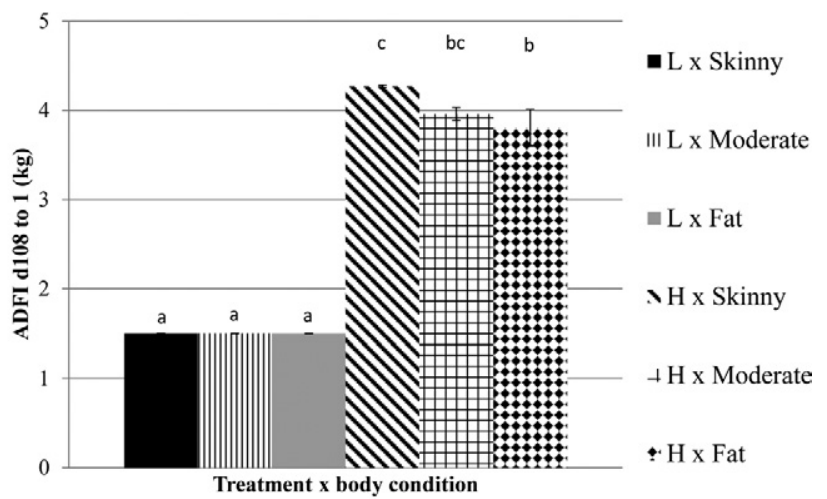

$\mathrm{H}$ : high feeding level during the peripartal period

L: low feeding level during the peripartal period

Figure 2. The ADFI between d 108 of gestation and d 1 of lactation for both treatment groups interacted with body condition group. Means without a common letter superscript differ $(P<0.05)$.

colostrum per $\mathrm{kg} \mathrm{BW}_{\mathrm{B}}$ were 1.38 times higher in the $\mathrm{L}$ group than piglets in the $\mathrm{H}$ group.

\section{Colostrum Composition}

Macronutrient and Immunoglobulin Composition. The percentage of colostral protein was lower for the $\mathrm{H}$ group compared with the $\mathrm{L}$ group $(P=0.040)$ and lower for skinny sows compared with fat sows $(P=0.048)$. Total $\mathrm{g}$ of colostral protein output did not differ between treatment groups and tended to be greater for sows in moderate $\mathrm{BC}$ compared with fat sows $(P=0.077)$. Percentage of lactose was greater for the $\mathrm{H}$ group compared with the $\mathrm{L}$ group $(P=0.009)$ and tended to be greater for skinny sows compared with fat sows $(P=0.060)$. Total $\mathrm{g}$ of lactose output was greater for the $\mathrm{H}$ group compared with the $\mathrm{L}$ group $(P=0.001)$. Fat sows had a lower total lactose output than skinny sows $(P=0.005)$ and tended to have a lower lactose output than sows in a moderate

Table 2. Feed intake, back fat and back fat change for treatment (TR), and body condition groups at d 108 of gestation (BC). Interaction terms were tested but were not significant $(P>0.05)$.

\begin{tabular}{|c|c|c|c|c|c|c|c|c|}
\hline \multirow[b]{2}{*}{ Variable $^{1}$} & \multicolumn{2}{|c|}{ TR } & \multicolumn{3}{|c|}{$\mathrm{BC}$} & \multirow[b]{2}{*}{ SEM } & \multicolumn{2}{|c|}{$P$} \\
\hline & $\mathrm{H}^{2}$ & $\mathrm{~L}^{3}$ & Skinny & Moderate & Fat & & TR & $\mathrm{BC}$ \\
\hline ADFI lactation, $\mathrm{kg}$ & 5.3 & 5.8 & 5.7 & 5.6 & 5.4 & 0.1 & 0.166 & 0.648 \\
\hline FI ${ }^{1} \mathrm{~d} 108$ to weaning, $\mathrm{kg}$ & $129^{\mathrm{A}}$ & $117^{\mathrm{B}}$ & 126 & 123 & 118 & 2.9 & 0.054 & 0.650 \\
\hline $\mathrm{BF}^{2} \mathrm{~d} 85, \mathrm{~mm}$ & 18.5 & 19.2 & $13.4^{\mathrm{a}}$ & $18.9^{\mathrm{b}}$ & $24.6^{\mathrm{c}}$ & 0.7 & 0.553 & $<0.001$ \\
\hline $\mathrm{BF} \mathrm{d} 108, \mathrm{~mm}$ & 19.4 & 19.6 & $12.8^{\mathrm{a}}$ & $19.7^{b}$ & $26.5^{\mathrm{c}}$ & 0.8 & 0.876 & $<0.001$ \\
\hline$\Delta \mathrm{BF}^{3} \mathrm{~d} 85$ to $108, \mathrm{~mm}$ & 0.9 & 0.4 & $-0.7^{\mathrm{a}}$ & $0.8^{\mathrm{ab}}$ & $1.9^{b}$ & 0.3 & 0.353 & 0.004 \\
\hline$\Delta \mathrm{BF} \mathrm{d} 108$ to $1, \mathrm{~mm}$ & $-0.05^{b}$ & $-1.7^{\mathrm{a}}$ & -0.8 & -1.0 & -1.1 & 0.2 & 0.001 & 0.004 \\
\hline$\Delta \mathrm{BF}$ lactation, $\mathrm{mm}$ & $-2.6^{\mathrm{a}}$ & $-1.6^{b}$ & $-0.7^{\mathrm{c}}$ & $-2.2^{b}$ & $-3.1^{\mathrm{a}}$ & 0.3 & 0.034 & 0.002 \\
\hline$\Delta \mathrm{BF}$ d 108 to weaning, $\mathrm{mm}$ & -2.6 & -3.3 & $-1.5^{\mathrm{b}}$ & $-3.2^{\mathrm{a}}$ & $-4.2^{\mathrm{a}}$ & 0.2 & 0.188 & $<0.001$ \\
\hline
\end{tabular}

${ }^{\mathrm{a}-\mathrm{c} W i t h i n}$ a row and within main effect, means without a common letter superscript differ $(P<0.05)$.

${ }^{\mathrm{A}, \mathrm{B} W i t h i n}$ a row and within main effect, means without a common symbol superscript tend to $\operatorname{differ}(0.05<P<0.10)$.

${ }^{1} \mathrm{FI}=$ feed intake; $\mathrm{BF}=$ back fat; $\mathbf{\Delta B} \mathbf{F}=$ back fat change

${ }^{2} \mathrm{H}=$ high feeding level during the peripartal period.

${ }^{3} \mathrm{~L}=$ low feeding level during the peripartal period. 
Table 3. Colostrum yield (CY) and macronutrient and immunoglobulin composition of colostrum in treatment (TR) and body condition groups at $\mathrm{d} 108$ of gestation $(\mathrm{BC})$. Interaction terms were tested but were not significant $(P>0.05)$

\begin{tabular}{|c|c|c|c|c|c|c|c|c|}
\hline \multirow[b]{2}{*}{ Variable } & \multicolumn{2}{|c|}{ TR } & \multicolumn{3}{|c|}{$\mathrm{BC}$} & \multirow[b]{2}{*}{ SEM } & \multicolumn{2}{|c|}{$P$} \\
\hline & $\mathrm{H}^{1}$ & $\mathrm{~L}^{2}$ & Skinny & Moderate & Fat & & TR & $\mathrm{BC}$ \\
\hline \multicolumn{9}{|l|}{$\overline{\mathrm{CY}}$} \\
\hline Total CY, g & $3,999^{\mathrm{A}}$ & $3,508^{\mathrm{B}}$ & $3,874^{\mathrm{ab}}$ & $3,991^{\mathrm{b}}$ & $3,163^{\mathrm{a}}$ & 141 & 0.074 & 0.036 \\
\hline CY/liveborn piglet, $\mathrm{g}$ & 312 & 287 & $297^{\mathrm{ab}}$ & $345^{\mathrm{b}}$ & $230^{\mathrm{a}}$ & 17 & 0.435 & 0.016 \\
\hline $\mathrm{CY} / \mathrm{kg}$ liveborn piglet, $\mathrm{g}$ & $239^{\mathrm{b}}$ & $200^{\mathrm{a}}$ & $215^{\mathrm{ab}}$ & $245^{\mathrm{b}}$ & $178^{\mathrm{a}}$ & 9 & 0.018 & 0.005 \\
\hline \multicolumn{9}{|l|}{ Colostrum composition } \\
\hline$\%$ protein & $14.7^{\mathrm{a}}$ & $15.3^{\mathrm{b}}$ & $14.5^{\mathrm{a}}$ & $15.2^{\mathrm{ab}}$ & $15.4^{\mathrm{b}}$ & 0.1 & 0.040 & 0.040 \\
\hline$\%$ lactose & $2.5^{\mathrm{b}}$ & $2.2^{\mathrm{a}}$ & $2.5^{\mathrm{A}}$ & $2.3^{\mathrm{AB}}$ & $2.2^{\mathrm{B}}$ & 0.1 & 0.009 & 0.057 \\
\hline$\% \mathrm{DM}$ & 22.2 & 22.7 & $21.7^{\mathrm{a}}$ & $22.4^{\mathrm{ab}}$ & $23.4^{\mathrm{b}}$ & 0.2 & 0.225 & 0.018 \\
\hline Total fat, $\mathrm{g}$ & 195 & 183 & 184 & 196 & 183 & 9 & 0.540 & 0.819 \\
\hline Total protein, $g$ & 589 & 531 & $558^{\mathrm{AB}}$ & $605^{\mathrm{A}}$ & $487^{\mathrm{B}}$ & 22 & 0.185 & 0.081 \\
\hline $\mathrm{IgG}, \mathrm{mg} / \mathrm{mL}$ & 50.1 & 59.0 & 65.0 & 39.1 & 47.5 & 4.2 & 0.620 & 0.123 \\
\hline $\operatorname{IgA}, \mathrm{mg} / \mathrm{mL}$ & 9.8 & 10.0 & $8.3^{\mathrm{B}}$ & $10.4^{\mathrm{AB}}$ & $11.0^{\mathrm{A}}$ & 0.52 & 0.828 & 0.097 \\
\hline Total IgG, g & 202 & 208 & 249 & 209 & 153 & 18 & 0.786 & 0.127 \\
\hline Total IgA, g & 37.7 & 35.2 & 31.0 & 41.8 & 33.8 & 2.3 & 0.665 & 0.124 \\
\hline
\end{tabular}

BC $(P=0.053)$. Percentage of colostral DM was greater for fat sows compared with skinny sows $(P=0.017)$, but this difference was not observed when total output of colostral DM was considered. Fat sows tended to have a greater concentration of IgA compared with skinny sows $(P=0.062)$. The concentration of IgG and total output of IgG and IgA did not differ across treatment or BC groups. Macronutrient and immunoglobulin composition of colostrum are shown in Table 3.

Amino Acids and Fatty Acids Composition. Concentration of essential $(P=0.015)$ and nonessential AA $(P=0.009)$ was greater for sows in the L group compared with the $\mathrm{H}$ group and lower for skinny sows compared to the other BC groups (essential AA: $P=0.010$, nonessential AA: $P=0.009$ ). Total colostral output of essential and nonessential AA did not differ between treatment and BC groups. Details are shown in Table 4.

Sows in the H group had greater colostral concentrations of MUFA, n-6 PUFA, n-3 PUFA, linoleic acid, and linolenic acid and a lower concentration of arachidonic acid compared with the L group (for all $p<0.001$ ). The (n6):(n-3) ratio was lower for sows in the $\mathrm{H}$ group compared with sows in the $\mathrm{L}$ group $(P=0.008)$. Fat sows had lower concentrations of SFA compared with the other $\mathrm{BC}$ groups $(P=0.001)$. Concentration of n-6 PUFA $(P=0.050)$ and linoleic acid $(P=0.033)$ was greater for fat sows than for skinny sows. The fatty acid composition is shown in Table 4 .

\section{(Re)productive Performance}

Parity $(5 \pm 1)$, gestation length $(115 \pm 1 \mathrm{~d})$, farrowing duration $(257 \pm 18 \mathrm{~min})$, average birth interval $(20 \pm$ $2 \mathrm{~min})$, total born $(15 \pm 0.5)$, liveborn $(14 \pm 4)$ and stillborn piglets $(0 \pm 1)$, number of piglets that died before $(1 \pm 2)$ and after $(0 \pm 1)$ cross fostering, and percentage of stillborn piglets $(0 \pm 6.8 \%)$ and percentage of piglets that died after cross fostering $(0 \pm 9.1 \%)$ did not differ between treatment and $\mathrm{BC}$ groups. Percentage of piglets that died before cross fostering tended $(P=0.075)$ to be greater in the $\mathrm{H}$ group $(10.1 \pm 10.8 \%)$ than in the L group $(6.7 \pm 18.3 \%)$, and no differences across BC groups were observed $(7.4 \pm 16.5 \%)$.

Piglets' $\mathrm{BW}_{\mathrm{B}}, \mathrm{BW}_{24}$, and weight gain during different periods of lactation is shown in Table 5. Litter weight gain between birth and $24 \mathrm{~h}$ of age tended to be greater for the $\mathrm{H}$ group compared with the L group $(P=0.058)$ and was lower for fat sows compared with sows in moderate $\mathrm{BC}(P=$ 0.031 ). Average piglet weight gain between birth and $24 \mathrm{~h}$ of age was lower for fat sows than for sows in moderate BC $(P=0.017)$. Litter $(P=0.013)$ and average $(P=0.006)$ piglet weight gain between $\mathrm{d} 3$ and $\mathrm{d} 7$ of lactation was greater for fat sows than for skinny sows. Average piglet weight gain during lactation tended to be greater for sows in moderate $\mathrm{BC}$ compared with skinny sows $(P=0.064)$. 
Table 4. Amino acid and fatty acid composition of colostrum in treatment (TR) and body condition groups at d 108 of gestation $(\mathrm{BC})$. Interaction terms were tested but were not significant $(P>0.05)$

\begin{tabular}{|c|c|c|c|c|c|c|c|c|}
\hline \multirow[b]{2}{*}{ Variable $^{1}$} & \multicolumn{2}{|c|}{ TR } & \multicolumn{3}{|c|}{$\mathrm{BC}$} & \multirow[b]{2}{*}{$\mathrm{SEM} / \mathrm{IR}^{4}$} & \multicolumn{2}{|c|}{$P$} \\
\hline & $\mathrm{H}^{2}$ & $\mathrm{~L}^{3}$ & Skinny & Moderate & Fat & & TR & $\mathrm{BC}$ \\
\hline \multicolumn{9}{|l|}{ AA } \\
\hline $\mathrm{EAA}^{1}, \mathrm{mmol} / \mathrm{L}$ & $569^{\mathrm{a}}$ & $620^{\mathrm{b}}$ & $551^{\mathrm{a}}$ & $612^{b}$ & $627^{\mathrm{b}}$ & 11 & 0.015 & 0.010 \\
\hline $\mathrm{NEAA}^{2}, \mathrm{mmol} / \mathrm{L}$ & $447^{\mathrm{a}}$ & $491^{b}$ & $434^{\mathrm{a}}$ & $481^{b}$ & $497^{b}$ & 9 & 0.009 & 0.009 \\
\hline Total EAA, mmol & 2,151 & 2,282 & 2,124 & 2,438 & 1,977 & 93 & 0.490 & 0.109 \\
\hline Total NEAA, mmol & 1,795 & 1,700 & 1,678 & 1,917 & 1,564 & 74 & 0.536 & 0.128 \\
\hline MUFA & $33.0^{\mathrm{a}}$ & $37.1^{\mathrm{b}}$ & 35.0 & 35.1 & 35.9 & 0.4 & $<0.001$ & 0.406 \\
\hline *n-3 PUFA & $4.2^{\mathrm{b}}$ & $2.5^{\mathrm{a}}$ & 2.6 & 2.7 & 2.8 & 1.8 & $<0.001$ & 0.444 \\
\hline n-6 PUFA & $23.6^{\mathrm{b}}$ & $21.0^{\mathrm{a}}$ & $21.6^{\mathrm{a}}$ & $22.1^{\mathrm{ab}}$ & $22.8^{\mathrm{b}}$ & 0.3 & $<0.001$ & 0.030 \\
\hline *(n-6):(n-3) PUFA & $5.5^{\mathrm{a}}$ & $8.6^{b}$ & 8.9 & 7.9 & 8.1 & 3.5 & 0.008 & 0.782 \\
\hline Linoleic acid n-6 C18:2 & $21.8^{\mathrm{b}}$ & $18.8^{\mathrm{a}}$ & $19.6^{\mathrm{a}}$ & $20.1^{\mathrm{ab}}$ & $20.8^{\mathrm{b}}$ & 0.3 & $<0.001$ & 0.017 \\
\hline DHA $^{5}$ n-3 C22:6 & 0.2 & 0.2 & 0.3 & 0.2 & 0.2 & 0.005 & 0.338 & 0.369 \\
\hline
\end{tabular}

\section{Blood Parameters Sow}

Concentrations of the blood parameters are shown in Table 6. At d 108 of gestation, fat sows tended to have a lower creatinine concentration than sows in moderate $\mathrm{BC}(P=0.097)$. At $\mathrm{d} 1$ of lactation, sows in the $\mathrm{H}$ group had a greater concentration of urea $(P=0.001)$, a lower concentration of creatinine $(p<0.001)$, NEFA $(P=0.002), \mathrm{C} 4(P=0.016), 3-\mathrm{OH}-\mathrm{C} 4(p<0.001)$, and $\operatorname{IgA}(P=0.044)$. Sows in moderate $\mathrm{BC}$ tended to have a greater concentration of creatinine than fat sows $(P=$ $0.084)$ and a greater concentration of $C 4$ compared with other BC groups $(P=0.083)$. The ratio urea/NEFA $(p<$ $0.001)$ and creatinine/NEFA $(P=0.015)$ was greater for sow in the $\mathrm{H}$ group compared to sows in the $\mathrm{L}$ group.

\section{DISCUSSION}

Both CY and (nutritional) composition were influenced by the sows' BC and the peripartal feeding strategy with the effect of these 2 being mainly independent. The highest $\mathrm{CY}$ and the highest colostral output of nutrients was achieved when sows entered the farrowing unit in a moderate $\mathrm{BC}$ (17 to $23 \mathrm{~mm} \mathrm{BF}$ ) and were provided with a high peripartal feeding strategy.

Feeding sows ad libitum for prolonged periods during gestation reduced voluntary feed intake during lactation (Weldon et al., 1994; Prunier et al., 2001; Sinclair et al., 2001; van der Peet-Schwering et al., 2004). However, when sows were fed ad libitum only during the week before farrowing, this decrease in feed intake was not observed (Cools et al., 2013), which corroborated with observations in this study. It is well described that sows' BC affects voluntary feed intake (Prunier et al., 2001; Young et al., 2004), and this was also observed in the H group as skinny sows had a greater ADFI compared with other sows the week before farrowing. A similar BF change was observed for both treatment groups between d 108 of gestation and weaning, but the period in which this change was achieved differed. The $\mathrm{H}$ group lost less BF during the week before farrowing, which was expected due to the greater ADFI, but lost more $\mathrm{BF}$ during lactation. It was assumed that this is not due to a greater milk production because piglet weight gain did not differ across treatment groups. The ADFI during lactation was $0.5 \mathrm{~kg}$ lower in the $\mathrm{H}$ group compared with the L group, which was not statistically significant but might have been biologically relevant and could explain the difference in $\mathrm{BF}$ change. The sows' BC at d 108 of gestation did not affect the BF change the week before farrowing, but skinny sows lost less BF during lactation compared with other sows. This was similar to results reported by Cools et al. (2014).

Total CY (1.7 to $5.7 \mathrm{~kg}$ ) was within normal ranges according to literature (Devillers et al., 2004; Foisnet et al., 2010; Decaluwé et al., 2013). Dourmad et al. (1999) stated that the effect of feed restriction at the end of 
Table 5. Piglets' birth weight and weight gain during lactation in treatment (TR) and body condition groups at d 108 of gestation $(\mathrm{BC})$. Interaction terms were tested but were not significant $(P>0.05)$

\begin{tabular}{|c|c|c|c|c|c|c|c|c|}
\hline \multirow[b]{2}{*}{ Variable $^{1}$} & \multicolumn{2}{|c|}{ TR } & \multicolumn{3}{|c|}{$\mathrm{BC}$} & \multirow[b]{2}{*}{ SEM } & \multicolumn{2}{|c|}{$P$} \\
\hline & $\mathrm{H}^{2}$ & $\mathrm{~L}^{3}$ & Skinny & Moderate & Fat & & TR & $\mathrm{BC}$ \\
\hline \multicolumn{9}{|c|}{ Litter weight (gain), $\mathrm{kg}$} \\
\hline $\mathrm{BW}_{\mathrm{B}} \mathrm{LBP}$ & 17.3 & 18.1 & 18.5 & 16.9 & 18.2 & 0.5 & 0.952 & 0.995 \\
\hline $\mathrm{BW}_{\mathrm{B}} \mathrm{SBP}$ & 2.2 & 1.6 & 1.2 & 2.1 & 1.8 & 0.3 & 0.304 & 0.645 \\
\hline 0 to $24 \mathrm{~h}$ & $1.4^{\mathrm{A}}$ & $1.0^{\mathrm{B}}$ & $1.2^{\mathrm{ab}}$ & $1.4^{\mathrm{b}}$ & $0.8^{\mathrm{a}}$ & 0.1 & 0.058 & 0.029 \\
\hline 7 to $14 d$ & 17.1 & 17.0 & 15.5 & 18.4 & 17.5 & 0.6 & 0.961 & 0.169 \\
\hline $14 \mathrm{~d}$ to weaning & 9.6 & 10.6 & 9.3 & 11.0 & 9.8 & 0.5 & 0.161 & 0.080 \\
\hline 0 to weaning & 39.5 & 40.0 & 36.0 & 42.1 & 40.5 & 1.3 & 0.880 & 0.136 \\
\hline \multicolumn{9}{|c|}{ Average piglet weight (gain), kg } \\
\hline $\mathrm{BW}_{\mathrm{B}} \mathrm{TBP}$ & 1.3 & 1.4 & 1.3 & 1.4 & 1.3 & 0.04 & 0.321 & 0.592 \\
\hline $24 \mathrm{~h}$ to $3 \mathrm{~d}$ & 0.26 & 0.28 & 0.26 & 0.29 & 0.26 & 0.01 & 0.491 & 0.035 \\
\hline 3 to $7 \mathrm{~d}$ & 0.77 & 0.74 & $0.66^{\mathrm{a}}$ & $0.77^{\mathrm{ab}}$ & $0.85^{\mathrm{b}}$ & 0.02 & 0.629 & 0.003 \\
\hline 7 to $14 d$ & 1.55 & 1.46 & 1.36 & 1.57 & 1.54 & 0.05 & 0.780 & 0.006 \\
\hline $14 \mathrm{~d}$ to weaning & 0.90 & 0.94 & 0.84 & 1.01 & 0.88 & 0.04 & 0.474 & 0.128 \\
\hline 0 to weaning & 3.6 & 3.5 & $3.2^{\mathrm{B}}$ & $3.8^{\mathrm{A}}$ & $3.6^{\mathrm{BA}}$ & 0.1 & 0.572 & 0.060 \\
\hline
\end{tabular}

gestation on CY would be rather small because sows compensate by mobilizing their body reserves. Sows in the L group indeed mobilized more body fat and protein reserves, as was indicated by the change in BF the week before farrowing and serum concentrations of NEFA, creatinine, and $\mathrm{C} 4$ at $\mathrm{d} 1$ of lactation. Nonetheless, this mobilization of body reserves seemed insufficient to fully compensate for reduced intake of nutrients because CY was lower. These findings supported the statement of Noblet et al. (1997) that adapting feeding strategies to the sows' needs at different periods during the reproductive cycle was critical for minimizing the difference between actual and potential performance of the sows.

Housing and management up to d 108 of gestation, BF at Day 108 of gestation, BF change between Day 85 and 108 of gestation, and serum parameters at d 108 of gestation did not differ between treatment groups and were within ranges reported earlier by Verheyen et al. (2007). It was, therefore, assumed that the physiological background of sows at the start of the treatment was similar for both treatment groups. The difference in CY between treatment groups had to result from the difference in feed intake in the week before farrowing and we hypothesized that the greater $\mathrm{CY}$ in the $\mathrm{H}$ group resulted from the increased availability of nutrients. Around farrowing, sows' metabolism adapts to spare glucose for fetuses and mammary secretion by guiding the maternal metabolism towards a greater use of energy substrates derived from fat (Boyd and Kensinger, 1998). These ketogenic energy substrates enter the citric acid cycle as acetyl-CoA and should react with oxaloacetate, which can originate from glucose and AA. The availability of oxaloacetate can be easily depleted when fat mobilization is high, putting pressure on the sows' metabolism. This pressure can be lowered by decreasing precursors of acetyl-CoA and increasing precursors of oxaloacetate. This situation was achieved in sows receiving the high feeding strategy as they mobilized less body fat reserves but had more protein catabolites available, as was shown by the BF change the week before farrowing and serum concentrations of NEFA, urea, and the ratio urea/NEFA. The greater availability of protein catabolites in the $\mathrm{H}$ group did not originate from the body protein reserves because there were lower concentrations of creatinine and $\mathrm{C} 4$ at $\mathrm{d} 1$ of lactation and thus had to originate directly from the feed. When the acetylCoA that is delivered to the citric acid cycle exceeds the availability of oxaloacetate, it is converted to ketone bodies (Theil et al., 2013). These ketone bodies (3-OHC4) were greater in the L group. 
Table 6. Serum and plasma biochemical variables at d 108 of gestation and d 1 of lactation in treatment (TR) and body condition groups at $\mathrm{d} 108$ of gestation $(\mathrm{BC})$. Interaction terms were tested but were not significant $(P>0.05)$

\begin{tabular}{|c|c|c|c|c|c|c|c|c|c|}
\hline \multirow[b]{2}{*}{ Time } & \multirow[b]{2}{*}{ Variable $^{1}$} & \multicolumn{2}{|c|}{ TR } & \multicolumn{3}{|c|}{$\mathrm{BC}$} & \multirow[b]{2}{*}{$\mathrm{SEM} / \mathrm{IR}^{4}$} & \multicolumn{2}{|c|}{$P$} \\
\hline & & $\mathrm{H}^{2}$ & $\mathrm{~L}^{3}$ & Skinny & Moderate & Fat & & TR & $\mathrm{BC}$ \\
\hline \multirow{6}{*}{ 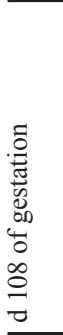 } & Urea, $\mathrm{mmol} / \mathrm{L}$ & 4.4 & 4.3 & 4.7 & 4.0 & 4.5 & 0.2 & 0.758 & 0.217 \\
\hline & Creatinine, $\mu \mathrm{mol} / \mathrm{L}$ & 233 & 238 & $242^{\mathrm{AB}}$ & $241^{B}$ & $221^{\mathrm{A}}$ & 4 & 0.530 & 0.059 \\
\hline & Glucose, $\mathrm{mmol} / \mathrm{L}$ & 3.2 & 3.2 & 3.1 & 3.2 & 3.2 & 0.1 & 0.549 & 0.728 \\
\hline & NEFA, mmol/L & 0.7 & 0.6 & 0.6 & 0.6 & 0.7 & 0.1 & 0.434 & 0.650 \\
\hline & $\mathrm{C} 4, \mu \mathrm{mol} / \mathrm{L}$ & 0.2 & 0.3 & 0.2 & 0.3 & 0.2 & 0.01 & 0.150 & 0.434 \\
\hline & $\mathrm{IgA}, \mathrm{mg} / \mathrm{mL}$ & 1.8 & 2.1 & 1.8 & 2.1 & 1.9 & 0.1 & 0.519 & 0.720 \\
\hline \multirow{7}{*}{ 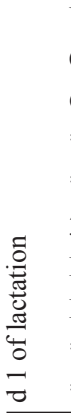 } & Urea, $\mathrm{mmol} / \mathrm{L}$ & $4.4^{\mathrm{b}}$ & $3.6^{\mathrm{a}}$ & 4.3 & 3.9 & 3.8 & 0.1 & 0.001 & 0.138 \\
\hline & Creatinine, $\mu \mathrm{mol} / \mathrm{L}$ & $214^{\mathrm{a}}$ & $263^{\mathrm{b}}$ & $247^{\mathrm{AB}}$ & $246^{\mathrm{B}}$ & $229^{\mathrm{A}}$ & 5 & $<0.001$ & 0.038 \\
\hline & Glucose, mmol/L & 4.0 & 3.9 & 3.9 & 4.0 & 3.9 & 0.5 & 0.898 & 0.532 \\
\hline & *NEFA, mmol/L & $0.2^{\mathrm{a}}$ & $0.5^{\mathrm{b}}$ & 0.2 & 0.3 & 0.5 & 0.4 & 0.002 & 0.331 \\
\hline & $\mathrm{IgA}, \mathrm{mg} / \mathrm{mL}$ & $1.9^{\mathrm{b}}$ & $1.3^{\mathrm{a}}$ & 1.4 & 1.6 & 1.5 & 0.1 & 0.034 & 0.776 \\
\hline & *Urea:NEFA & $28^{\mathrm{b}}$ & $8^{\mathrm{a}}$ & 19 & 10 & 9 & 23 & $<0.001$ & 0.260 \\
\hline & *Creatinine:NEFA & $1.2^{\mathrm{b}}$ & $0.6^{\mathrm{a}}$ & 1.2 & 0.9 & 0.5 & 1.3 & 0.047 & 0.371 \\
\hline
\end{tabular}

A high feeding strategy in the week before farrowing thus reduced pressure on the maternal energy metabolism, but it also increased the amount of nutrients secreted through colostrum as shown by the increased content of lactose and several fatty acids. Glucose is the precursor of lactose (Shennan and Peaker, 2000), but plasma glucose concentration at $\mathrm{d} 1$ of lactation did not differ between treatment groups, although intake of glucose precursors through feed differed 3-fold. This could be explained by the fasted state of the sows at the time of sampling, indicating that plasma glucose already returned to basal levels. Nonetheless, the greater concentration and total output of lactose in colostrum in the $\mathrm{H}$ group showed that more glucose delivered to the mammary gland was available for lactose production. Based on this experiment, it could not be concluded whether this was a result of a greater glucose delivery to the mammary gland, a decreased use of glucose for other processes than lactose production (Boyd and Kensinger, 1998), or a combination of both. The fatty acid profile of sow colostrum is mainly a reflection of the fat composition of the diet (Farmer and Quesnel, 2009), but colostral fat originates from the diet as well as from body fat reserves and de novo synthesis in the mammary gland (Boyd and Kensinger, 1998). In this study, all sows were offered the same diet, but the fatty acid profile of the diet was better reflected in colostrum of the H group, although concentration and total fat output in colostrum did not differ between treatment groups. In the L group, the relative share of fatty acids in colostrum originating from the diet was smaller. Thus, the fatty acid profile in sows' colostrum could be altered by adapting the feed composition (Farmer and Quesnel, 2009), but this might only be successful when a certain level of feed intake was achieved. The protein content of colostrum in the H group was lower compared with the L group, but the total output of colostral protein did not differ. When sows were provided the same feeding level the week before farrowing, there was no association between colostrum protein content and CY (Decaluwé et al., 2013). In this study, nutrient intake the week before farrowing differed across experimental groups and perhaps a dilution effect of the colostral protein with nutritional value was induced because the difference in colostral protein content was not due to differences in Ig-content. As most colostral protein with nutritional value is synthesized within the alveolar cells of the mammary gland (Devillers et al., 2006), a dilution effect should mean that the synthesis of colostral protein was not increased by greater ADFI or was already at its maximal capacity with lower ADFI. However, the origin of AA for this alveolar protein synthesis might have differed, as sows in the L group had to mobilize a greater amount of body protein compared to sows in the $\mathrm{H}$ group. 
The serum concentration of $\operatorname{IgA}$ at $\mathrm{d} 1$ of lactation was greater in the $\mathrm{H}$ group compared with the L group, but this did not result in differences in IgA concentration or total output in colostrum, which might be due to the fact that approximately $60 \%$ of colostral IgA is synthesized by plasmocytes in the mammary gland (Salmon et al., 2009).

In contrast to the treatment groups, differences in $\mathrm{CY}$ and composition across $\mathrm{BC}$ groups did not seem to be due to physiological differences in the week before farrowing, as most blood variables at d 108 of gestation and $\mathrm{d} 1$ of lactation and the BF change in the week before farrowing did not differ across BC groups. Still, $\mathrm{BF}$ change between d 85 and $\mathrm{d} 108$ of gestation differed across $\mathrm{BC}$ groups, levels of creatinine tended to be lower in fat sows compared to sows in moderate $\mathrm{BC}$, and voluntary ADFI was lower for fat than for skinny sows the week before farrowing within the $\mathrm{H}$ group. It was, therefore, assumed that the physiological background at $\mathrm{d}$ 108 of gestation differed across BC groups and that this might have been the underlying cause of the observed differences across $\mathrm{BC}$ groups. Leptin and insulin are 2 major metabolic parameters regulating energy metabolism (Barb et al., 2001). Père and Etienne (2007) showed that insulin sensitivity of all sows decreased from d 85 of gestation onward but that this was more prominent for fat sows, and concentration of leptin varies with the amount of body fat (Barb et al., 2001).

Reproductive performance of sows did not differ between treatment groups and $\mathrm{BC}$ groups. The observed changes in piglets' weight gain during the first $24 \mathrm{~h}$ of life was greater in the groups with the highest CY. During the whole lactation period, piglets from skinny sows had the lowest weight gain whereas feeding strategy did not affect piglet weight gain. Cross fostering might have affected these results but this will have been minimal as only $5 \%$ of piglets were removed from the trial at $\mathrm{d} 2$ of lactation. The effect of the increased CY and intake in the $\mathrm{H}$ group was probably too low to affect piglet performance in this trial.

In conclusion, both $\mathrm{CY}$ and composition were influenced by sows' body condition and the peripartal feeding strategy, with the effects being mainly independent of each other. The highest CY and the highest colostral output of nutrients was achieved when sows entered the farrowing unit in moderate condition and were provided with the high peripartal feeding strategy.

\section{LITERATURE CITED}

Barb, C. R., G. J. Hausman, and K. L. Houseknecht. 2001. Biology of leptin in the pig. Domest. Anim. Endocrinol. 21:297-317.

Boyd, R. D., and R. S. Kensinger. 1998. Metabolic precursors for milk synthesis. In: M. W. A. Verstegen, P. J. Moughan, and J. W. Schrama, editors, The lactating sow. Wageningen Pers, Wageningen, The Netherlands. p. 76-79.
Chouinard, P. Y., V. Girard, and G. J. Brisson. 1997. Performance and profiles of milk fatty acids of cows fed full fat, heat-treated soybeans using various processing methods. J. Dairy Sci. 80:334-342.

Coffey, M. T., R. W. Seerley, and J. W. Mabry. 1982. The effect of source of supplemental dietary energy on sow milk yield, milk composition and litter performance. J. Anim. Sci. 55:1388-1394.

Cools, A., D. Maes, R. Decaluwé, J. Buyse, T. A. van Kempen, and G. P. Janssens. 2013. Peripartum changes in orexigenic and anorexigenic hormones in relation to back fat thickness and feeding strategy of sows. Domest. Anim. Endocrinol. 45:22-27.

Cools, A., Maes D., Decaluwé R., Buyse J., van Kempen T. A. T. G., Liesegang A., and Janssens G. P. J. 2014. Ad libitum feeding during the peripartal period affects body condition, reproduction results and metabolism of sows. Anim. Repr. Sci. 145:130-140.

Decaluwé, R., D. Maes, I. Declerck, A. Cools, B. Wuyts, S. De Smet, and G. P. J. Janssens. 2013. Changes in back fat thickness during late gestation predict colostrum yield in sows. Animal 7:1999-2007.

Devillers, N., J. Le Dividich, and A. Prunier. 2006. Physiologie de la production de colostrum chez la truie. INRA Prod. Anim. 19:29-38.

Devillers, N., J. van Milgen, A. Prunier, and J. Le Dividich. 2004. Estimation of colostrum intake in the neonatal pig. Anim. Sci. 78:305-313.

Dourmad, J. Y., M. C. Père, and M. Etienne. 1999. Impact de la nutrition sur les évènements de la mise bas chez la truie. 2èmes rencontres porcine Schering-Plough Vétérinaire, De J-2 à J+2 autour de la mise bas. (In French.) Schering-Plough Vét, Saint Malo, France. p. 29-42.

Ellendorf, F., M. L. Forsling, and D. A. Poulain. 1982. The milk ejection reflex in the pig. J. Physiol. 333:577-594.

Farmer, C., and H. Quesnel. 2009. Nutritional, hormonal, and environmental effects on colostrum in sows. J. Anim. Sci. 87:56-64.

Foisnet, A., C. Farmer, C. David, and H. Quesnel. 2010. Relationship between colostrum production by primiparous sows and physiology around parturition. J. Anim. Sci. 88:1672-1683.

Jackson, J. R., W. L. Hurley, R. A. Easter, A. H. Jensen, and J. Odle. 1995. Effects of induced or delayed parturition and supplemental dietary fat on colostrum and milk composition in sows. J. Anim. Sci. 73:1906-1913.

Le Dividich, J., J. A. Rooke, and P. Herpin. 2005. Nutritional and immunological importance of colostrum for the new-born pig. J. Agric. Sci. 143:469-485.

Lewis, A. J. 2001. Amino acids in swine nutrition. In: A. J. Lewis and L. L. Southern, editors, Swine nutrition. CRC Press, Boca Raton, FL. p. 133-135.

Maes, D. G. D., G. P. J. Janssens, P. Delputte, A. Lammertyn, and A. de Kruif. 2004. Back fat measurements in sows from three commercial pig herds: Relationship with reproductive efficiency and correlation with visual body condition scores. Livest. Prod. Sci. 91:57-67.

Martineau, G. P., Y. Le Treut, D. Guillou, and A. Waret-Szkuta. 2013. Postpartum dysgalactia syndrome: A simple change in homeorhesis? J. Swine Health Prod. 21:85-93.

Michal, G. 1999a. Amino acids and derivatives. In: G. Michal, editor, Biochemical pathways: An atlas of biochemistry and molecular biology. John Wiley and Sons, New York. p. 57-58.

Michal, G. 1999b. Carbohydrate metabolism and citrate cycle. In: G. Michal, editor, Biochemical pathways: An atlas of biochemistry and molecular biology. John Wiley and Sons, New York. p. 43.

Noblet, J., J. Y. Dourmad, M. Etienne, and J. Le Dividich. 1997. Energy metabolism in pregnant sows and newborn pigs. J. Anim. Sci. 75:2708-2714.

Père, M. C., and M. Etienne. 2007. Insulin sensitivity during pregnancy, lactation, and postweaning in primiparous gilts. J. Anim. Sci. 85:101-110. 
Prunier, A., C. A. M. Guadarrama, J. Mourot, and H. Quesnel. 2001. Influence of feed intake during pregnancy and lactation on fat body reserve mobilisation, plasma leptin and reproductive function of primiparous lactating sows. Reprod. Nutr. Dev. 41:333-347.

Salmon, H., M. Berri, V. Gerdts, and F. Meurens. 2009. Humoral and cellular factors of maternal immunity in swine. Dev. Comp. Immunol. 33:384-393.

Shennan, D. B., and M. Peaker. 2000. Transport of milk constituents by the mammary gland. Physiol. Rev. 80:925-951.

Sinclair, A. G., V. C. Bland, and S. A. Edwards. 2001. The influence of gestation feeding strategy on body composition of gilts at farrowing and response to dietary protein in a modified lactation. J. Anim. Sci. 79:2397-2405.

Stefanov, I., B. Vlaeminck, and V. Fievez. 2010. A novel procedure for routine milk fat extraction based on dichloromethane. J. Food Compost. Anal. 23:852-855.

Theil, P. K., A. K. Olesen, C. Flummer, G. Sorensen, and N. B. Kristensen. 2013. Impact of feeding and post prandial time on plasma ketone bodies in sows during transition and lactation. J. Anim. Sci. 91:772-782.

Thiex, N. 2002. Feeds. J. AOAC Int. 85:270-273.
Verheyen, A. J. M., D. G. D. Maes, B. Mateusen, P. Deprez, G. P. J. Janssens, L. de Lange, and G. Counotte. 2007. Serum biochemical reference values for gestating and lactating sows. Vet. J. 174:92-98.

van der Peet-Schwering, C. M. C., B. Kemp, G. P. Binnendijk, L. A. den Hartog, P. F. G. Vereijken, and M. W. A. Verstegen. 2004. Effects of additional starch or fat in late-gestation high nonstarch polysaccharide diets on litter performance and glucose tolerance in sows. J. Anim. Sci. 82:2964-2971.

Weldon, W. C., A. C. Lewis, G. F. Louis, J. L. Kovar, M. A. Gieseman, and P. S. Miller. 1994. Postpartum hypophagia in sows: I. Effects of gestation feeding level on feed intake, feeding behavior, and plasma metabolite concentrations during lactation. J. Anim. Sci. 72:387-394.

Young, M. G., M. D. Tokach, F. X. Aherne, R. G. Main, S. S. Dritz, R. D. Goodband, and L. Nelssen. 2004. Comparison of three methods of feeding sows in gestation and the subsequent effects on lactation performance. J. Anim. Sci. 82:3058-3070.

Zabielski, R., Z. Gajewski, P. J. L. Valverde, D. Laubitz, J. Wilczak, B. Balasinska, and G. Kulasek. 2007. The perinatal development of the gastrointestinal tract in piglets can be modified by supplementation of sow diet with bioactive substances. Livest. Sci. 109:34-37. 
References

This article cites 29 articles, 13 of which you can access for free at: http://www.journalofanimalscience.org/content/92/8/3557\#BIBL 